\title{
Evaluate Patient's Awareness Regarding Significance of Pre-Anesthetic Checkup for Elective Surgery in Western Libya
}

\author{
Marwan T. M. Abofila ${ }^{1}$, Azab Elsayed Azab ${ }^{2 *}$, Asmahan A. A. Mouni ${ }^{3}$, Abojela Ramadan ${ }^{4}$, Aisha \\ Mukhtar Hadi Hassan ${ }^{5}$, Awatef Miloud Ali Skeha ${ }^{6}$, Wejdan Abdulkarim Emhmed Alkhader ${ }^{7}$ \\ Hala Abdelhafeez Hadi Aburas ${ }^{8}$ \\ ${ }^{1}$ Department of Anatomy, Histology and Embryology, Faculty of Medicine, Sabratha University, Libya. \\ ${ }^{2}$ Department of Physiology, Faculty of Medicine, Sabratha University, Libya. \\ ${ }^{3}$ Department of Psychology, Faculty of Arts-Zawia, Zawia University, Libya. \\ ${ }^{4-8}$ Department of Anesthesia \& Intensive Care, Faculty of Medical Technology-Surman \\ Sabratha University, Libya. \\ azabelsaied@yahoo.com \\ *Corressponding Author: Azab Elsayed Azab, Department of Physiology, Faculty of Medicine, Sabratha University, Libya.
}

Abstract

Background: Large proportion patients believe that pre-anesthetic checkup is unnecessary and a waste of time and money. Patients in some cases shows a lack of interest during the pre-anesthesia check or attempts to rush through, which may results to an incomplete case history, general physical examination and laboratory investigations. These compromise patient care and may affect health state.

Objectives: The aims of the present study was to evaluate the knowledge and perception of adult patients presenting for elective surgery in Sabratha and Surman public hospitals regarding the value and importance of pre-anesthesia checkup, and to investigate the effect of patients' variables on patient's Knowledge and perception for pre anesthesia checkup.

Methodology: This study was conducted in Sabratha and Surman public hospitals in western Libya, over a period of 4 month. Forty Patients were asked to fill a questionnaire consisting of 15 questions before start of pre anesthesia assessment. Each question was provided with multiple possible choices, out of which patient had to choose the most appropriate in his or her opinion. Scoring was done by awarded 1 mark for correct answer while incorrect answer was given 0 marks. Statistical Analysis for data were stated as frequencies, percentages, means and standard deviations.

Results: Our results revealed that around $62.5 \%$ of patients had overall percentage for positive responses $\geq 50$ $\%$, while the rest had $<50 \%$. The total score of positive responses for all patients were 257 represented (58.4\%) of overall percentage while the total score of negative responses for all patients were 183 represented (41.6\%) of overall percentage. Patients' variables included ages, educational levels, and previous visit for anesthesia assessment had significant effect on patient's knowledge and perception regarding pre anesthesia checkup. While gender had not significant effect on them.

Conclusion: Large ratio of patients had insufficient knowledge and inadequate perception about preanesthesia checkup and its role in improving the patient care and the outcome of surgery. Also, we assumption that whenever patient in urban area increase in age, education level and previous experience for pre-anesthesia assessment, that will increase patient's knowledge and perception for the value and the importance of pre anesthesia check-up.

Keywords: Patient's awareness, Pre-anesthetic checkup, Urban area, Western Libya. 
Evaluate Patient's Awareness Regarding Significance of Pre-Anesthetic Checkup for Elective Surgery in Western Libya

\section{INTRODUCTION}

Surgery concerned with diagnosis and treatment of injury, deformity, disease and other disorders [1]. Elective surgery is one of the most common type of surgery [2]. The pain involved in elective surgery and other surgery types without using anesthesia will be a source of discomfort, intolerance and inability to bear it [3]. Anesthesia as a profession has shifted from a simple specialty of surgical support to an involvement in the comprehensive and healthy care of patients, not only in the operating room but also in intensive care units and clinical pain [4].

Despite this, the knowledge of the general public, patients, paramedical personnel, and even surgeons regarding various aspects of anesthesia are limited[5].

Numerous studies conducted in the past have shown limited awareness among members of the community in common with the patients about various aspects of anesthesia [6]. But nowadays, patients recognize the importance of anesthesia and the role of anesthesiologist at the time of surgery and even during the postoperative period. However, pre anesthetic checkup still remains a less cared aspect of anesthesia [7].

It is a well-established fact that pre-anesthetic checkup is an essential aspect of patient care. Pre-anesthetic checkup includes history taking, appropriate physical examination and laboratory tests. The purpose of pre-anesthetic control is to optimize a patient prior to surgery to minimize the risk of anesthesia and surgery and to improve outcomes. In addition, it offers the patient the opportunity to discuss any questions or concerns regarding anesthesia [8]. However, large proportion of patients in many places believe that pre anesthetic checkup is unnecessary and a waste of time and money. All of that may lead to a lack of patient interest during the procedure of pre anesthetic checkup and trying to rush through, which results to an incomplete case history, general physical examination and laboratory investigations. This may result in insufficient optimization of the patient prior to surgery and the task of the anesthesiologist becomes more difficult. Preoperative investigations is done for optimized advise and that is often seen by the most of patients as unnecessary and is not taken seriously [8]. Add to that increased patient load, lack of patient knowledge and perception regarding PAC, and an increasing number of elective surgeries being performed, and increasing the incidence of inadequate pre anesthesia check-up, which leads to compromise patient care, and uncertainty in the outcome of the surgery and anesthesia as well as increase preoperative rates of morbidity and mortality [9].

Patients need to understand that a comprehensive and pre-anesthetic evaluation and optimization greatly contributes to improving the operative outcomes. Not only patients, however, the general public should be educated on the value of various aspects of anesthesia [10]. In addition, misconceptions such as preanesthetic examination only delay surgeries should be strongly discouraged. On the other hand, if patients understand the purpose of PAC and fully cooperate during preoperative optimization, unnecessary delays and cancellations on the day of elective surgery could be avoided [11].

Appropriate understanding and interest of surgical patients would contribute to better communication between the patient and the anesthesiologist. This will result in greater patient satisfaction and reduced preoperative anxiety. In addition, this will help establish anesthesiologists as preoperative physicians in the minds of patients, which will lead to the development of the specialty [12].

\section{OBJECTIVES}

The aim of the present study was to evaluate the knowledge and perception of adult patients presenting for elective surgery in Sabratha and Surman public hospitals regarding the value and importance of preanesthesia check up. Also, it was to inspect the effect of patients' variables included ages, gender, educational levels and previous visit for anesthesia assessment on Patient's Knowledge and perception regarding pre anesthesia Checkup.

\section{METHODOLOGY}

\section{Study Design}

A cross-sectional descriptive study was conducted in Sabratha and Surman public Hospitals in western Libya for a period of 4 month from 1st July to the end of October 2019. Data were collected from patients in a modified Singla and Mangla ${ }^{[9]}$ questionnaire. The entire questionnaire was to be completed before start of pre-anesthetic check-up. Initial questions were preliminary data questions, which about Archives of Anesthesiology V3 . I1 . 2020 
patient's characteristics like age, sex, education level and previous visit to PAC (questions number 1-4). Afterward, questions were exploratory data questions, which around patient's views and understanding of pre-anesthesia check-up and its importance in patient care (questions number 5-15).

\section{Administrative Agreements}

The researchers obtain an approval from department of Anesthesia and Intensive Care, Faculty of Medical Technology - Sabratha University, Surman teaching hospitals, Oncology and teaching hospitals of Sabratha. Finally, written informed consent was obtained from all the patients before starting to answer the questionnaire.

\section{Sample of the Study}

The size of sample and a convenience data of (40) patients was targeted in this project (20 patients from Surman teaching Hospital, 10 patients from Sabratha teaching hospital and 10 patients from oncology hospital in Sabratha) posted for elective surgery coming to pre anesthesia checkup.

\section{Data Collection}

Data were collected by the interview with each individual as mean of data collection process. Patients were asked to fill a Questionnaire consisting of 15 questions before start of PAC.

Ages of patients were range between 18 and 67 years of age, both male and female were involved in present study, as well as different education levels were involved in our study. Patients with hearing problems, unable to speak and with altered mental status will excluded from the study. If any patient reject to answer

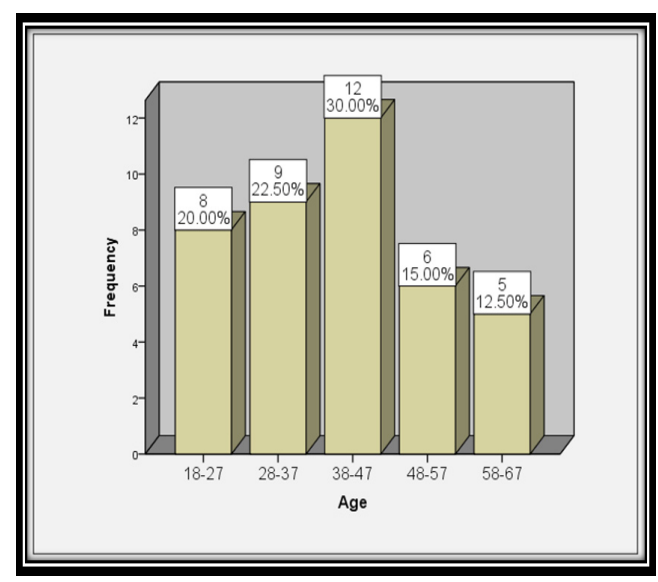

Figure 1. Sample distribution based on age. the questionnaire, he/she will also excluded from the study.

Each question was provided with multiple possible choices, out of which patient had to choose the most appropriate according to him/her. An option of do not know was also provided with most question. Scoring was done for question 5 to 15 , with each question answered correctly was awarded 1 mark while incorrect answer was given 0 marks. Patients giving do not know as answer were also given 0 marks

\section{Statistical Analysis}

Statistical analysis was done by using SPSS version 25 (Statistical Packages for Social Sciences) for windows by IBM for this study. Data were expressed as frequencies, percentage statistical mean and standard deviation. Unpaired t-test and one way analysis of variance were used to compare between different parameters. $\mathrm{P}<0.05$ was considered statistically significant.

\section{RESULTS AND DisCUSSION}

\section{Sample Characteristics}

A total of 40 patients aged between 18 - 67 years. Coming to public hospitals for pre-anesthesia checkup answered the questionnaire. About $20 \%$ of the patients were in aged group between 18 - 27 years. Around $22.5 \%$ of the patients were in aged group between $28-37$ years. In addition, $30 \%$ of the patients were in aged group between 38 - 47 years. Moreover, $15 \%$ of the patients were in aged group between $48-57$ years. While the rest of the patients were between 58 - 67 years of age. Sample distribution based on Age are shown in (Figure 1). $40 \%$ of the patients were males and $60 \%$ were female (Figure 2).

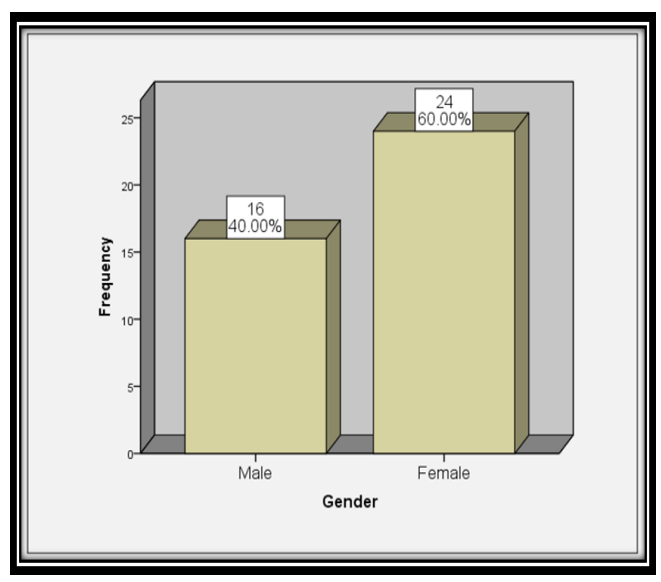

Figure 2. Sample distribution based on gender. 
As far as education level were concerned, zero percentage of the patients were illiterates because few of illiterate's patients were found and all of them were refused to fill a questionnaire. Only $5 \%$ of patients had studies up to primary school. Around $22.5 \%$ of the patients had continued their studied up to preparatory school. About $22.5 \%$ of the patients were finished secondary school.

Merely, $45 \%$ of the patients were graduate from

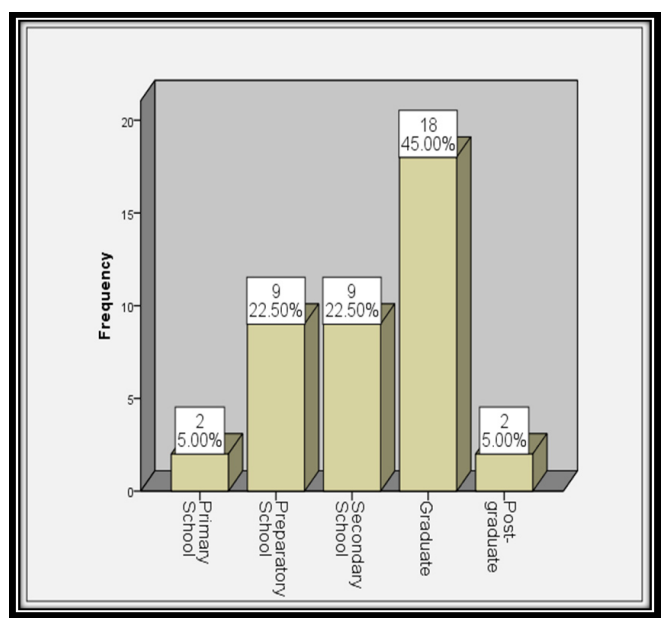

Figure 4. Sample distribution based on previous visit for pre anesthesia assessment.

Patient's Knowledge and Perception of Pre Anesthesia Checkup

On being asked, what they had thought the reason behind doing pre anesthetic checkup. Only 30\% of the patients answered for pre anesthesia assessment, while $22.5 \%$ of the patients said that they were following surgeon's instructions, and $40 \%$ of the patients believed that they would be getting date for surgery there, the rest $7.5 \%$ of the patients did not know the exact reason.

In reply to question what is done in a pre-anesthesia checkup, 35\% believed that only general assessment of patient done before anesthesia; only $17.5 \%$ said that assessment, optimization \& risk stratification before surgery, rest $37.5 \%$ thought some test would be performed to assess anesthesia fitness and 10\% were not sure.

Similarly, only $52.5 \%$ (Table 2) of the patients knew that only anesthesiologist can perform a pre anesthesia checkup, $35 \%$ of patients were said that Doctor sitting in clinic would perform a pre anesthesia checkup, while $7.5 \%$ of patients believed that a pre anesthesia different faculties. Moreover, the rest $5 \%$ of the patients were postgraduate. Sample distribution based on education Level are shown in (Figure 3).

Nearly, $63 \%$ of the patients had a previous visit to preanesthesia assessment. While the rest of the patients nearby $37 \%$ were coming for the first time visit to pre-anesthesia checkup. Sample distribution based on previous visit for pre anesthesia assessment are shown in (Figure 4).

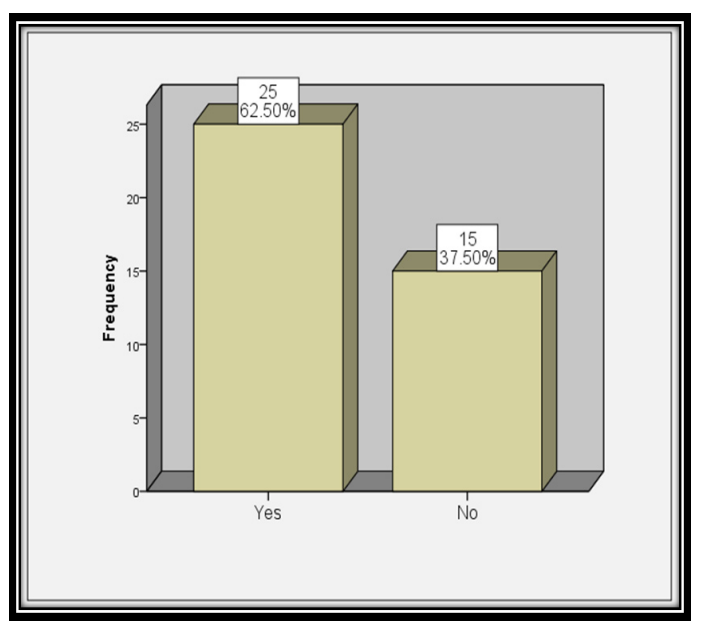

Figure 3. Sample distribution based on education level

checkup can perform by nurse or technician in clinic. The rest $5 \%$ of the patients were not know. Only $60 \%$ thought that pre anesthesia checkup helps to reduce surgery and anesthesia-related risk. While $25 \%$ of the patients believed that was required to get data for surgery. The remained $15 \%$ of the patients were not sure.

On being asked the significance of preoperative morbid conditions, exactly $95 \%$ believed that they are to be told before surgery, the rest $5 \%$ of the patients were not know. $72.5 \%$ of the patients said that such conditions are required to be optimized before surgery while $2.5 \%$ believed that such conditions were not required to be optimized before surgery. Only $25 \%$ of the patients thought that such conditions do not required to be optimized before surgery if not related to surgical condition. And only $65 \%$ knew that presence of such conditions might affect the outcome of anesthesia and surgery while $10 \%$ of the patient said that presence of such conditions were not affect the outcome of anesthesia and surgery. The rest $25 \%$ were not sure. As far as habits like drinking and smoking are concerned only $77.5 \%$ said that these 
Evaluate Patient's Awareness Regarding Significance of Pre-Anesthetic Checkup for Elective Surgery in Western Libya

conditions might affect anesthesia or surgery. While $2.5 \%$ though opposite. The remained $20 \%$ of the patients were not know.

When patients were asked if pre anesthesia checkup is required only for surgery were performed under anesthesia, $37.5 \%$ of the patients were agreed. While $42.5 \%$ of the patients were disagreed. The rest $20 \%$ of the patients were not sure

Similarly, only $42.5 \%$ of the patients said that they would discuss their fears or queries regarding anesthesia during visit the anesthesiologist before surgery. While $27.5 \%$ of the patients said that, they

Table 1. Patients' response to questionnaire

\begin{tabular}{|c|c|c|c|}
\hline Questions & Response & $\begin{array}{l}\text { Total } \\
\text { Score } \\
\end{array}$ & $\begin{array}{l}\text { Overall } \\
\text { Percent }\end{array}$ \\
\hline \multirow{4}{*}{$\begin{array}{l}\text { What do you think the } \\
\text { reason behind doing the } \\
\text { pre-anesthesia checkup? }\end{array}$} & To comply with surgeons instructions & 9 & $22.5 \%$ \\
\hline & To get data for surgery & 16 & $40 \%$ \\
\hline & For pre anesthesia assessment & 12 & $30 \%$ \\
\hline & I do not know & 3 & $7.5 \%$ \\
\hline \multirow{4}{*}{$\begin{array}{l}\text { What will be done in the } \\
\text { pre-anesthesia checkup? }\end{array}$} & General assessment of patient done before anesthesia & 14 & $35 \%$ \\
\hline & Some test is to be performed to assess anesthesia fitness & 15 & $37.5 \%$ \\
\hline & $\begin{array}{l}\text { Assessment, optimization \& risk stratification before } \\
\text { surgery }\end{array}$ & 7 & $17.5 \%$ \\
\hline & I do not know & 4 & $10 \%$ \\
\hline \multirow{4}{*}{$\begin{array}{l}\text { Who can perform the pre- } \\
\text { anesthesia checkup? }\end{array}$} & Nurse/technician in clinic & 3 & $7.5 \%$ \\
\hline & Doctor sitting in clinic & 14 & $35 \%$ \\
\hline & Anesthesiologist in clinic & 21 & $52.5 \%$ \\
\hline & I do not know & 2 & $5 \%$ \\
\hline \multirow{4}{*}{$\begin{array}{l}\text { What is the important of } \\
\text { pre-anesthesia checkup } \\
\text { before surgery? }\end{array}$} & Reduce the risk of anesthesia \& surgery & 24 & $60 \%$ \\
\hline & Required to get data for surgery & 10 & $25 \%$ \\
\hline & Legal documentation & 0 & $0 \%$ \\
\hline & I do not know & 6 & $15 \%$ \\
\hline \multirow{4}{*}{$\begin{array}{l}\text { Are condition like heart } \\
\text { disease, breathing } \\
\text { difficulties, renal problems } \\
\text { have to be expressed before } \\
\text { surgery? }\end{array}$} & Yes & 38 & $95 \%$ \\
\hline & No & 0 & $0 \%$ \\
\hline & Not if well controlled & 0 & $0 \%$ \\
\hline & I do not know & 2 & $5 \%$ \\
\hline \multirow{4}{*}{$\begin{array}{l}\text { If there is a preexisting } \\
\text { medical condition, does } \\
\text { it needs to be optimized } \\
\text { before surgery? }\end{array}$} & Yes & 29 & $72.5 \%$ \\
\hline & No & 1 & $2.5 \%$ \\
\hline & Not required if not related to surgical condition & 10 & $25 \%$ \\
\hline & I do not know & 0 & $0 \%$ \\
\hline \multirow{3}{*}{$\begin{array}{l}\text { Are above mentioned } \\
\text { conditions affect outcome of } \\
\text { anesthesia \& surgery? }\end{array}$} & Yes & 26 & $65 \%$ \\
\hline & No & 4 & $10 \%$ \\
\hline & I do not know & 10 & $25 \%$ \\
\hline
\end{tabular}

Archives of Anesthesiology V3 . I1 . 2020 share such feeling with the surgeon in ward. In addition, $12.5 \%$ of the patients would share such were not know.

Only $72.5 \%$ patients said that they follow preanesthesia checkup advice for their own good. 15\% said they would follow pre anesthesia advice only till surgery is performed, $7.5 \%$ said that they would do so only if the surgeon advises same. while $5 \%$ were not sure. Distribution of patients' response to questionnaire regarding patient's knowledge and perception for pre anesthesia checkup are shown in (Table 1). feeling in operation theatre. The $17.5 \%$ of patients 
Evaluate Patient's Awareness Regarding Significance of Pre-Anesthetic Checkup for Elective Surgery in Western Libya

\begin{tabular}{|l|l|c|c|}
\hline \hline \multirow{2}{*}{$\begin{array}{l}\text { Does habits like drinking or } \\
\text { smoking affect outcome of } \\
\text { anesthesia \& surgery? }\end{array}$} & Yes & 31 & $77.5 \%$ \\
\cline { 2 - 4 } & I do not know & 1 & $2.5 \%$ \\
\hline $\begin{array}{l}\text { Is pre-anesthesia checkup } \\
\text { required only when surgery } \\
\text { is to be performed under } \\
\text { anesthesia? }\end{array}$ & Yes & 15 & $20 \%$ \\
\cline { 2 - 4 } & No & 17 & $42.5 \%$ \\
\hline \multirow{2}{*}{$\begin{array}{l}\text { When should you discuss } \\
\text { your fear/quarries } \\
\text { regarding anesthesia (if } \\
\text { any)? }\end{array}$} & During visit the anesthesiologist before surgery & 8 & $20 \%$ \\
\cline { 2 - 4 } & In ward with surgery & 17 & $42.5 \%$ \\
\cline { 2 - 4 } & In operation theatre & 11 & $27.5 \%$ \\
\hline \multirow{2}{*}{$\begin{array}{l}\text { Do you follow any advice } \\
\text { you will get in the pre- } \\
\text { anesthesia checkup? }\end{array}$} & Y do not know & 5 & $12.5 \%$ \\
\cline { 2 - 4 } & Yes, till surgery is performed & 29 & $72.5 \%$ \\
\cline { 2 - 4 } & Only if surgeon say so & 6 & $15 \%$ \\
\cline { 2 - 4 } & I do not know & $2.5 \%$ \\
\hline
\end{tabular}

Generally, based on overall percent \& total Score for true and false patients' responses to questionnaire. The true patients' responses were named positive response while false patients' responses were entitled negative responses. In this study the total positive response were 257 points, which represented about

$56.4 \%$ of total score for all question to entire patients. While the total negative responses were 183 points that represented approximately $41.6 \%$ of total score for all question to entire patients. Distribution of patients' response based on total score for positive \& negative responses are shown in (Figure 5).

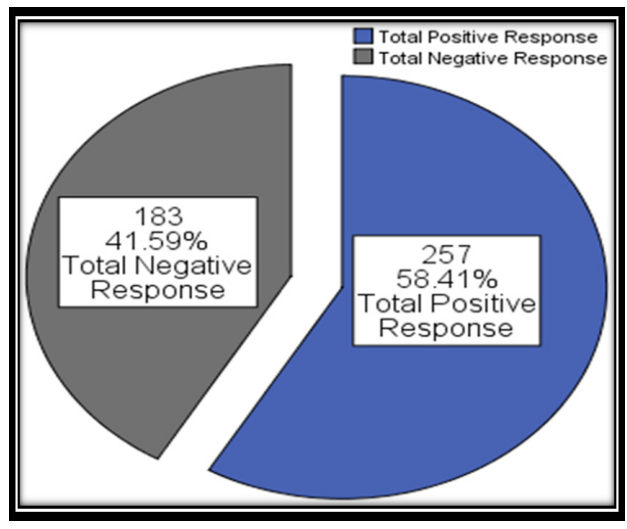

Figure 5. Patients' response distribution based on total score for positive and negative responses

Inclusive, according to overall percent and total score of positive patients responses to questionnaire, patients were divided in two group include patients' pass group whom got $\geq 50 \%$ of total positive score, which they represented

Table 2. Distribution of patient's pass or not pass based on overall percent \& total score of positive responses

\begin{tabular}{|c|c|c|c|}
\hline Valid & Frequency & Percent & $\begin{array}{c}\text { Overall Percent of Total } \\
\text { positive responses }\end{array}$ \\
\hline Pass & 25 & $62.5 \%$ & $\geq 50 \%$ \\
\hline Not Pass & 15 & $37.5 \%$ & $<50 \%$ \\
\hline Total & 40 & $100 \%$ & $100 \%$ \\
\hline
\end{tabular}


Evaluate Patient's Awareness Regarding Significance of Pre-Anesthetic Checkup for Elective Surgery in Western Libya

The patient awareness results compared with previous one is considered high, but the previous study was done by Singla and Mangla in a rural area [9] and our study is done in an urban area which means that the result we got is actually humble considering the area of study. Also, the size and characteristics of sample between two different countries may had effect in this study.

\section{Correlation Between Patient Variables and Patient Knowledge and Perception}

Statistical analysis were done for Impact of age, sex, education level, and previous experience of pre anesthetic checkup. Which illustrated that there was no significant correlation was found between gender of the patients and their knowledge perception of PAC. While there were significant correlation was found between ages, education level and previous visited of PAC for patients on one side and their knowledge and perception of PAC on other sides.

In present study show that there is effect of patient's age on knowledge and perception regarding pre anesthesia checkup which are shown in (Table 3)

Table 3. Effect of patient's age on knowledge \& perception regarding PAC

\begin{tabular}{|c|c|c|c|c|c|}
\hline Age & No. of Patients & Total score & Mean \pm SD & F test & $P$ value \\
\hline $18-27$ & 8 & 32 & $5.50 \pm 1.60$ & \multirow{5}{*}{3.029} & \multirow{5}{*}{0.030} \\
\hline 28-37 & 9 & 45 & $5.56 \pm 1.74$ & & \\
\hline $38-47$ & 12 & 94 & $7.83 \pm 2.72$ & & \\
\hline 48-57 & 6 & 47 & $5.00 \pm 2.83$ & & \\
\hline 58-67 & 5 & 39 & $7.80 \pm 1.30$ & & \\
\hline
\end{tabular}

Since P-value $=0.030<0.05$, it can be concluded that there is a significant difference between ages in terms of knowledge regarding pre anesthesia checkup. Using LSD (Least Square Method) to identify which age groups is different, it was found that ages (38$47),(48-57)$ and (58-67) had significantly higher knowledge regarding pre anesthesia checkup than ages (18-27) \& (28-37).

Our study revealed that there is a significant difference between ages in terms of knowledge and perception regarding pre anesthesia checkup. Which disagrees with previous study result illustrated by Singla and Mangla [9]. It could be caused of mental, moral, culture, geography differences between the urban and rural area. In addition, the size and characteristics of sample between two different countries may had effect in our study.

Our study show that there is no effect of patient's gender on knowledge and perception regarding pre anesthesia checkup that are shown in (Table 4).

Table 4. Effect of Patient's gender on knowledge and perception regarding PAC

\begin{tabular}{|c|c|c|c|c|c|}
\hline Gender & No. of Patients & $\begin{array}{c}\text { Total } \\
\text { score }\end{array}$ & Mean \pm SD & T test & P value \\
\hline Male & 16 & 92 & $5.75 \pm 2.38$ & -1.457 & 0.153 \\
\hline Female & 24 & 165 & $6.88 \pm 2.40$ & \\
\hline
\end{tabular}

Since P-value $=0.153>0.05$, it can be concluded that there is no significant difference between male and female in terms of knowledge regarding pre anesthesia checkup.

In present study illustrated that there is no significant difference between male and female in terms of knowledge and perception regarding pre anesthesia checkup. Which agrees with the previous studies. Similar results were obtained by Singla and Mangla in a study for Patient's knowledge and perception of pre anesthesia checkup in rural India ${ }^{[9]}$. Also, similar in research by Gurunathan and Jacob in a study regarding public's perception of the anesthesiologist in India [4]. Similarly in a study by Sagün et al. [13] though women showed higher knowledge of anesthesia, results were not statistically significant.

In this study show that there is effect of patient's education level on knowledge and perception regarding pre anesthesia checkup, which are shown in (Table 5). 
Evaluate Patient's Awareness Regarding Significance of Pre-Anesthetic Checkup for Elective Surgery in Western Libya

Table 5. Effect of patient's education level on knowledge and perception regarding pre anesthesia checkup

\begin{tabular}{|c|c|c|c|c|c|}
\hline Education Level & No. of Patients & $\begin{array}{l}\text { Total } \\
\text { score }\end{array}$ & Mean \pm SD & F test & P value \\
\hline Primary school & 2 & 11 & $5.50 \pm 0.71$ & \multirow{5}{*}{3.362} & \multirow{5}{*}{0.044} \\
\hline Preparatory School & 9 & 57 & $6.33 \pm 2.00$ & & \\
\hline Secondary school & 9 & 49 & $5.44 \pm 2.07$ & & \\
\hline Graduate & 18 & 121 & $6.72 \pm 2.74$ & & \\
\hline Post-graduate & 2 & 19 & $9.50 \pm 2.12$ & & \\
\hline
\end{tabular}

Since P-value $=0.044<0.05$, it can be concluded that there is a significant difference between education levels in terms of knowledge regarding pre anesthesia checkup. Using LSD (Least Square Method) to identify which education level is different, it was found that post graduates had significantly higher knowledge regarding pre anesthesia checkup than other education levels. There is no significant difference between primary school, preparatory school, secondary school and graduate in terms of knowledge regarding pre anesthesia checkup.
Impact of education level on the patients' knowledge and perception about pre anesthesia checkup was studied by Baaj et al. [14] and by Singla and Mangla [9] both were found to be directly related. Similar outcomes were obtained in this study.

This study demonstration that there is effect of previous visit for pre anesthesia assessment on knowledge and perception regarding pre anesthesia checkup, which are shown in (Table6).

Table 6. Effect of previous visit for pre anesthesia assessment on knowledge and perception regarding pre anesthesia checkup

\begin{tabular}{|c|c|c|c|c|c|}
\hline \multirow{y}{*}{ Visit } & No. of Patients & Total score & Mean \pm SD & T test & P value \\
\cline { 1 - 4 } Yes & 25 & 196 & $6.76 \pm 2.47$ & \multirow{2}{*}{1.131} & 0.037 \\
\cline { 1 - 5 } & 15 & 61 & $5.87 \pm 2.33$ & & \\
\hline
\end{tabular}

Since P-value $=0.037<0.05$, it can be concluded that there is no significant difference between patients who had previous visited for anesthesia assessment and whose not in terms of knowledge regarding pre anesthesia checkup. Using LSD (Least Square Method) to identify, which group is different, it was found group who had previous visited for anesthesia assessment had significantly higher knowledge regarding pre anesthesia checkup than other group whose not.

Influence of previous experience of pre anesthesia assessment on the knowledge and perception of pre anesthesia checkup were studied by Baaj et al. [14] and by Singla and Mangla [9] both were found to be directly related. Alike results were gotten in our study.

\section{ConCLUSION}

It can be concluded that large ratio of patients have insufficient awareness about pre anesthesia assessment \& its role in improving the outcome of surgery. Also, we assumption that whenever patient in urban area increase in age, education level and previous experience for pre anesthesia assessment, that will increase patient's knowledge and perception for the value and the importance of pre anesthesia checkup. Hence efforts should be made by not only anesthesiologist but also by surgeons and media involved in patient care to emphasize the importance of pre anesthetic checkup to decrease preoperative morbidity and mortality. It is clear that we recommended and emphasized on study the possible measures that can be taken to improve patient's knowledge and perception regarding pre anesthesia checkup and advance study are necessary to fully address this problem and improve patient care.

\section{REFERENCES}

[1] Patel V. V, Patel A, Harrop J. S, and Burger E. Spine surgery basics-part I general-surgical approaches. Springer, 2014; 3: 91-98. 
Evaluate Patient's Awareness Regarding Significance of Pre-Anesthetic Checkup for Elective Surgery in Western Libya

[2] Gupta D. Surgical suites' operations management. Production and Operations Management, 2007; 16: 689-700.

[3] Cramer G., Young B. M., Schwarzentraub P., Oliva C. M., and Racz G. Preemptive analgesia in elective surgery in patients with complex regional pain syndrome: a case report. The Journal of foot and ankle surgery, 2000; 39: 387-391.

[4] Gurunathan U, and Jacob R. The public's perception of anaesthesiologists - Indian attitudes. Indian J Anaesth., 2004; 48: 456-460.

[5] Irita K, and Takahashi S. Lack of communication between anesthesiologists and surgeons: Comparison of questionnaire survey among anesthesiologists with that among surgeons concerning pre-anesthetic evaluation of surgical patients. Masui, 2000; 49: 7-17.

[6] Chew ST, Tan T, Tan SS, Ip-Yam PC. A survey of patients' knowledge of anaesthesia and perioperative care. Singapore Med J., 1998; 39: 399-402.

[7] White P. F., and Kehlet H. Improving postoperative pain management: What are the unresolved issues? Anesthesiology: The Journal of the American Society of Anesthesiologists, 2010; 112: 220-225.
[8] Forrest JB, Rehder K, Cahalan MK, and Goldsmith $\mathrm{CH}$. Multicenter study of general anesthesia. III. Predictors of severe perioperative adverse outcomes. Anesthesiology, 1992; 76: 3-15.

[9] Singla D, and Mangla, M. Patient's knowledge and perception of pre-anesthesia check-up in rural India. Anesthesia, Essays and Researches, 2015: 9: 326-331

[10] Harms C, YoungJR, Amsler F, Zettler C, Scheidegger D, and Kindler CH. Improving anaesthetists' communication skills. Anaesthesia, 2004; 59: 166-172.

[11] Sagün A, Birbiçer H, and Yapici G. Patients' who applied to the anesthesia clinic, perceptions and knowledge about anesthesia in Türkiye. Saudi J Anaesth 2013;7:170-174.

[12] Baaj J, Takrouri MS, Hussein BM, Al Ayyaf H. Saudi patients' knowledge and attitude toward anesthesia and anesthesiologists - A prospective cross-sectional interview questionnaire. Middle East J Anaesthesiol., 2006; 18: 679-691.

Citation: Dr. Azab Elsayed Azab, Marwan T. M. Abofila, et al. Evaluate Patient's Awareness Regarding Significance of Pre-Anesthetic Checkup for Elective Surgery in Western Libya. Archives of Anesthesiology. 2020; 3(1): 01-09

Copyright: (C) 2020 : Dr. Azab Elsayed Azab, Marwan T. M. Abofila, et al. This is an open access article distributed under the Creative Commons Attribution License, which permits unrestricted use, distribution, and reproduction in any medium, provided the original work is properly cited. 